\title{
A Study \& Real Time Monitoring of Metal Oxide Semiconductor (MOS) Gas Sensor
}

\author{
Ajay Beniwal ${ }^{1}$, Naini Garg ${ }^{2}$, Sudeshna Bagchi ${ }^{3}$, Kirandeep ${ }^{4}, \mathrm{C}$ Ghanshyam ${ }^{5}$ and \\ C C Tripathi ${ }^{6}$ \\ ${ }^{I}$ (Assistant Professor, UIET, Kurukshetra University Kurukshetra - 136119, India) \\ ${ }^{2,4}$ (UCIM, Panjab University, Chandigarh - 160014, India) \\ ${ }^{3}$ (Scientist, Agrionics, CSIR-CSIO, Chandigarh - 160030, India) \\ ${ }^{5}$ (Chief Scientist, Agrionics, CSIR-CSIO, Chandigarh-160030, India) \\ ${ }^{6}$ (Professor, UIET, Kurukshetra University Kurukshetra - 136119, India)
}

\begin{abstract}
This paper provides comprehensive study of commercial gas sensor, TGS 822. This work reports the electrical characteristics like sensitivity, selectivity, response time \& recovery time. The sensor was exposed to different analytes at various concentration to study these characteristics, based on the change in resistance. The performance of the sensor including sensitivity, selectivity, response time and recovery time is summarized.Further a real time monitoring of analytes has been described with the help of NI-USB 6210 DAQ using lab view software.
\end{abstract}

Keywords - Alcohols, DAQ, Metal Oxide Semiconductor (MOS), Selectivity, Sensitivity, Sensors.

\section{INTRODUCTION}

Conduct metric metal oxide semiconductor (MOS) gas sensors have been studied and effectively used in the detection of various gases. Investigations on the gas sensors have indicated that surface reactions is strongly related to the gas sensing process [1]. Material used to create the sensing layer plays an important role in defining the characteristics and parameters of the gas sensors, most important parameters are sensitivity, selectivity, reproducibility, stability, response time, recovery time and reversibility. Metal oxides stand out as one of the most common, diverse and largest class of materials due to their extensive structural, physical and chemical properties. For sensing layers metal oxides like $\mathrm{SnO}_{2}, \mathrm{TiO}_{2}, \mathrm{ZnO}, \mathrm{WO}_{3}, \mathrm{Ga}_{2} \mathrm{O}_{3}, \mathrm{In}_{2} \mathrm{O}_{3}, \mathrm{Fe}_{2} \mathrm{O}_{3}$ are the most extensively used and widely applied in practical commercial sensors [2]. Taguchi gas sensors (TGS) are commercially available and quite popular because of their moderate durability and reasonable cost. TGS consists of a porous semiconductor layer (e.g. $\mathrm{SnO}_{2}, \mathrm{TiO}_{2}, \mathrm{WO}_{3}, \mathrm{ZnO}$ ) which is sensitive towards chemical analytes at elevated temperature, up to several hundred ${ }^{0} \mathrm{C}$ [3]. TGS 822 is most widely used for the detection of organic solvent vapors such as ethanol alcohol. The sensing layer of this gas sensor is a tin dioxide $\left(\mathrm{SnO}_{2}\right)$, has low conductivity in fresh air. In the presence of detectable analyte conductivity of the sensor get increases corresponding to the concentration of gas in the air [4-5]. NI-USB 6210 DAQ card is used to acquire the signals from the sensing chamber to perform the real time monitoring of analytes under test using Lab VIEW software. The aim of this paper is to study the sensing characteristics and parameters of commercial gas sensor and real time monitoring of gas sensor using NI USB 6210.

\section{EXPERIMENTAL}

The experimental set-up consist of gas sensing chamber, a source/measure unit (SMU) for I-V characterisation, a computer to display the output and a vacuum pump to vacuum the gas sensing chamber as shown in the Fig.1. The gas sensor (TGS) was placed inside the gas sensing chamber and on exposure to target analytes change in resistance was observed for different analytes at various concentrations. To calculate the various parameters like sensitivity, response time, recovery time etc., resistance of the gas sensor was measured in the absence and presence of the analytes and corresponding to the change in resistance above said parameters were calculated 


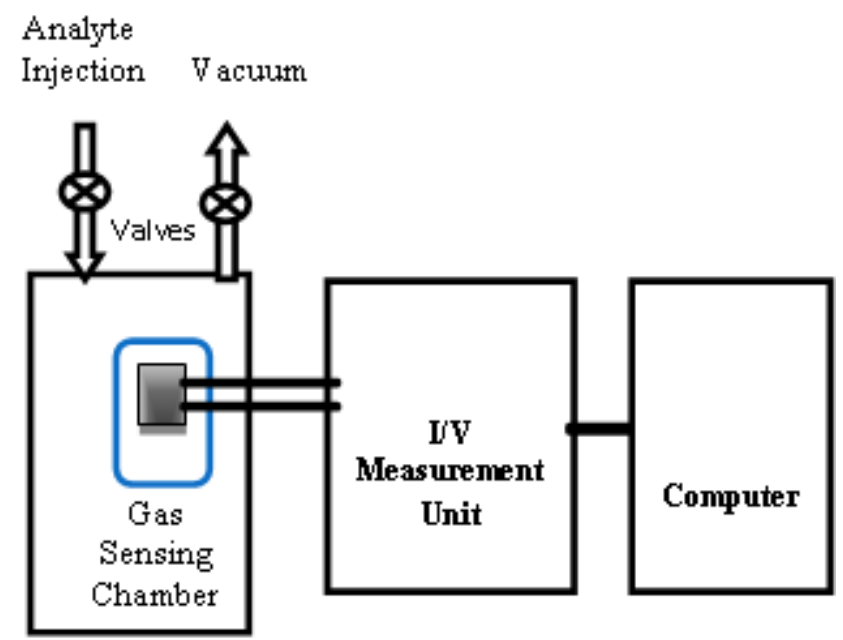

Fig.1 Gas Sensing Set-Up

To measure the change in resistance the procedure is defined in the Fig. 2. As shown in the Fig.2 initially when there was no gas in the chamber baseline resistance $\left(\mathrm{R}_{\text {base }}\right)$ was measured. On the application of the gas or chemical analyte there was change in resistance $(\Delta \mathrm{R})$ i.e. either the resistance will increase or decrease from the baseline resistance depending on the gas being inserted into the chamber.

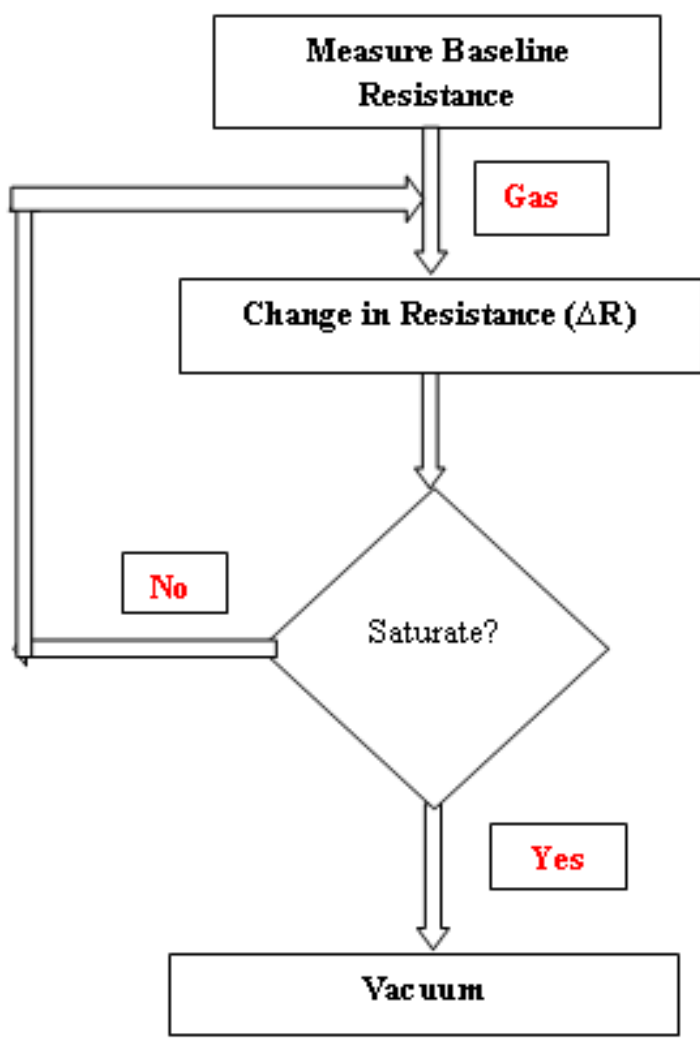

Fig. 2 Flow Chart of Experimental Procedure

Gas was inserted into the chamber continuously until the change in resistance get saturated. After this the chamber was cleaned by flushing out the inserted gas through vacuum pump. The same procedure was repeated for the different analytes at different concentrations. 
IOSR Journal of Electronics and Communication Engineering (IOSR-JECE)

e-ISSN: 2278-2834, p- ISSN: 2278-8735

List of the analytes used with their concentration are shown in the Table 1

Table I List of Analyses Used

\begin{tabular}{|c|c|c|}
\hline Sr. No. & Analyte Used & Concentration \\
\hline 1 & Ethanol & $1 \mathrm{ppm}-100 \mathrm{ppm}$ \\
\hline 2 & Methanol & $1 \mathrm{ppm}-100 \mathrm{ppm}$ \\
\hline 3 & Propanol & $1 \mathrm{ppm}-100 \mathrm{ppm}$ \\
\hline
\end{tabular}

For the analyses shown in Table 1, change in resistance was tested for TGS 822 commercial gas sensor at concentrations 1ppm, 10ppm, 50ppm, 75ppm \& 100ppm.

On exposure to the reducing gas the resistance of the n-type sensors decreases [6] and by measuring the change in the electrical resistance, the sensitivity was calculated as [7]:-

$$
\text { Sensitivity }(\mathrm{S})=\left(\mathrm{R}_{\text {base }}-\mathrm{R}_{\text {gas }}\right) / \mathrm{R}_{\text {base }}
$$

Where, $\mathrm{R}_{\mathrm{gas}}$ is the resistance of the sensor under gas exposure and $R_{\text {base }}$ the resistance of the sensor under air.

Same procedure was repeated for calculating the various parameters like sensitivity, selectivity, response time and recovery time etc. for each analyte at defined concentration. Table 2 shows the sensor with type and sensing layer material used.

Table II Description of Sensor

\begin{tabular}{|c|c|c|c|c|}
\hline Sr. No. & Gas Sensor & Type & Sensing Layer & Operating Temp. \\
\hline 1 & TGS 822 & n-Type & $\mathrm{SnO}_{2}$ & $300^{\circ} \mathrm{C}$ \\
\hline
\end{tabular}

\section{SENSOR DATA ACQUISITION}

A data acquisition system consists of sensor, DAQ measurement hardware (NI-USB 621X DAQ series) and a pc with programmable software (NI DAQ max driver software and Lab view signal express). Data acquisition hardware acts as the interface between the computer and the outside world.

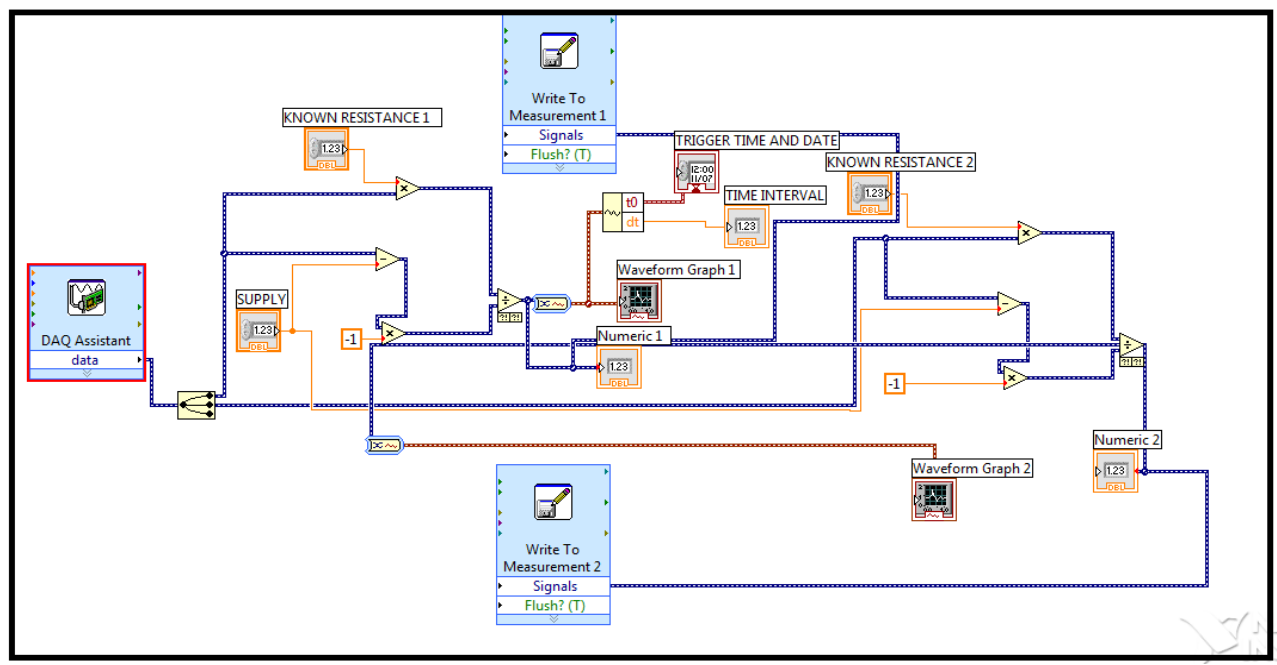

Fig. 3 LabVIEW Program

NI-USB 6210 DAQ card was used to acquire the signals from the sensing chamber. NI-USB 6210 consists of 32 pins including 16 analog inputs, 4 digital inputs, 4 digital outputs, 2 DGND, AIGND, AISENSE, Power supply, $2 \mathrm{NC}$ pins, and one of the pin is reserved. Following features are associated with USB 6210 [8]. The LabVIEW program was developed to acquire the signals from the sensors as shown in the Fig. 3. 
LabVIEW program consists of DAQ assistant that is used to acquire signal in the form of voltage from sensor. The acquired voltage signal is split using splitter and then converted to resistance using mathematical tools \& signal is displayed using waveform graph.

\section{RESULTS \& DISCUSSION}

Response as a function of Concentration - There was change in the sensitivity of the sensors as a function of concentration. Hence the sensors were exposed to analytes with varying concentration in the range $1 \mathrm{ppm}$ to 100 ppm. The change in sensitivity of different analytes as a function of concentration was studied [9-10].

Selectivity - The selectivity of a sensor was measured by exposing the sensor under different analytes and recording the sensor's response (change in resistance) more effectively towards a certain analytes as compare to others [11-13].

TGS 822 is a commercial gas sensor that is specifically used to detect the low concentration of ethanol alcohol. In addition to ethanol, its response was also analyzed for other alcohols. Fig. 3, Fig. 4 \& Fig. 5 shows the graphical results of TGS 822 gas sensor for ethanol, methanol \& propanol respectively and Table 3 shows the sensitivity of the sensor TGS 822 .

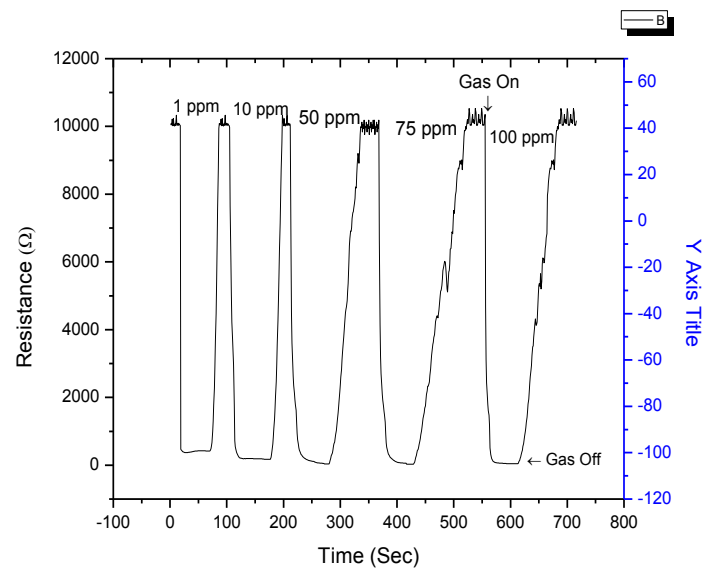

.Fig. 3 TGS 822 Ethanol Response (Resistance vs. Time) Graph

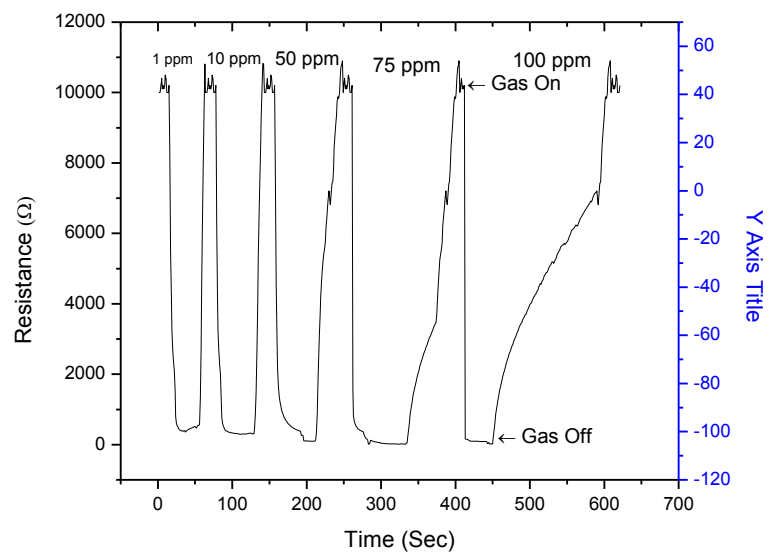

Fig. 4 TGS 822 Methanol Response (Resistance vs.

\section{Time) Graph}

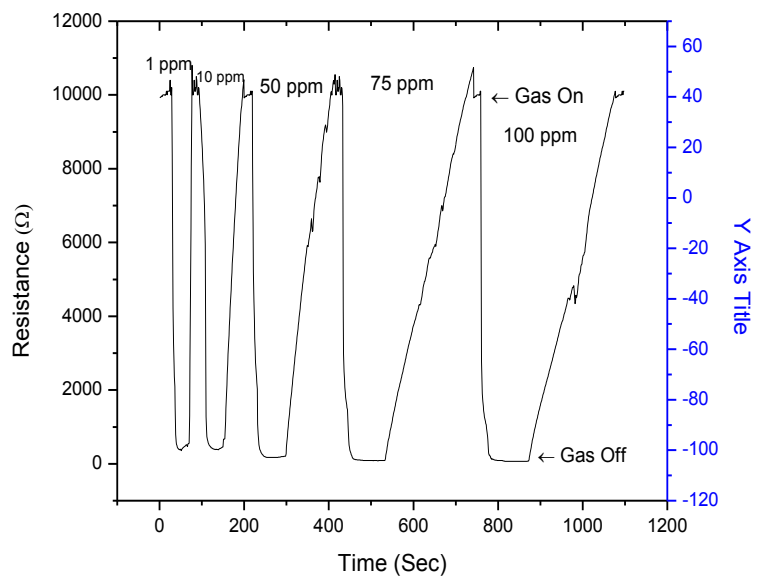

Fig. 5 TGS 822 Propanol Response (Resistance vs. Time) Graph

Table III - Sensitivity of TGS 822 Sensor

\begin{tabular}{|c|c|c|c|}
\hline Concentration & & Sensitivity & \\
\hline & Ethanol & Methanol & Propanol \\
\hline $\mathbf{1}$ ppm & 0.959 & 0.958 & 0.958 \\
\hline $\mathbf{1 0} \mathbf{~ p p m}$ & 0.982 & 0.970 & 0.962 \\
\hline $\mathbf{5 0} \mathbf{~ p p m}$ & 0.987 & 0.990 & 0.983 \\
\hline $\mathbf{7 5} \mathbf{~ p p m}$ & 0.994 & 0.994 & 0.991 \\
\hline $\mathbf{1 0 0} \mathbf{~ p p m}$ & 0.996 & 0.996 & 0.994 \\
\hline
\end{tabular}

Table III shows the sensitivity of the commercial gas sensor TGS 822 . Which is $0.959,0.958 \& 0.958$ at $1 \mathrm{ppm}$ and $0.996,0.996 \& 0.994$ at 100 ppm for ethanol, methanol \& propanol respectively, which is almost same for all the alcohols. According to table as the concentration of the analytes is increasing the sensitivity of the 
commercial sensor is also increasing. On the basis of Table 3, Fig. 6 shows the sensitivity vs. concentration graph of TGS 822 gas sensor for ethanol, methanol and propanol.

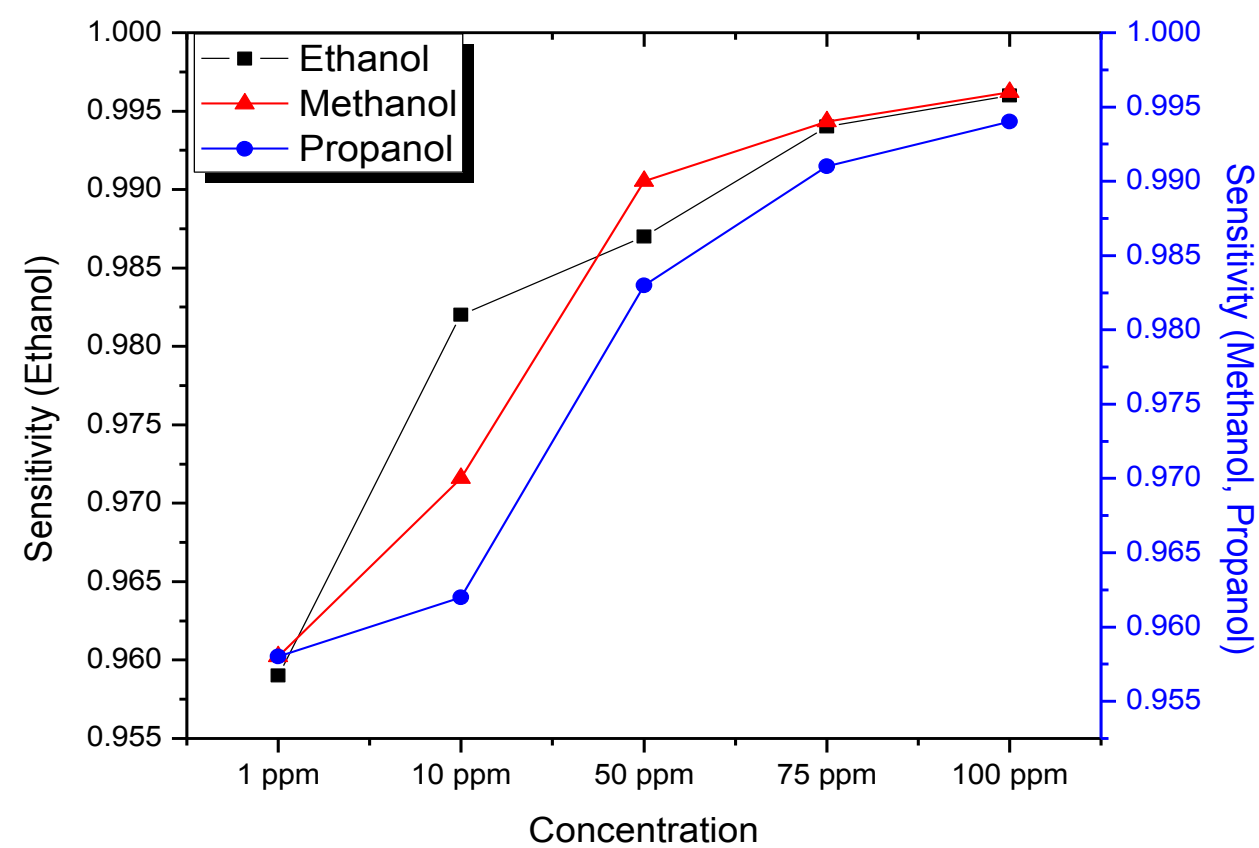

Fig. 6 TGS 822 Sensitivity vs. Concentration Graph

\section{RESULTS: REAL TIME MONITORING USING DAQ}

TGS 822 sensor was interfaced with the LabVIEW software \& according to the change in resistance, the front panel will display the values as shown in the Fig.7.Then the sensor was tested by introducing the same analytes into the sensing chamber at same concentrations and the response was recorded and compared with response obtained using source measure unit. Fig.8 shows the response of TGS 822 obtained in real time for the same analyte (methanol - $100 \mathrm{ppm}$ ) on the same time using NI USB DAQ 6210.

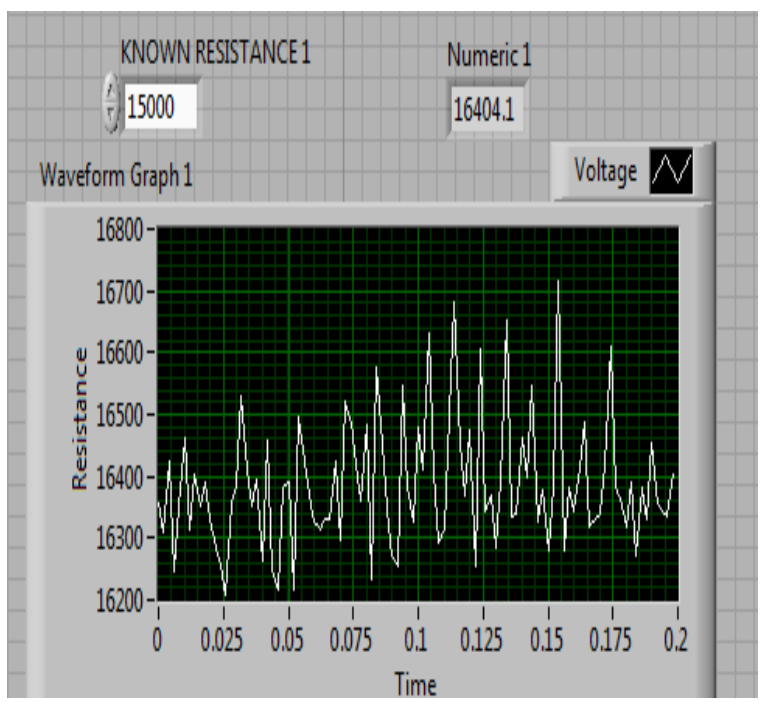

Fig.7 Front Panel

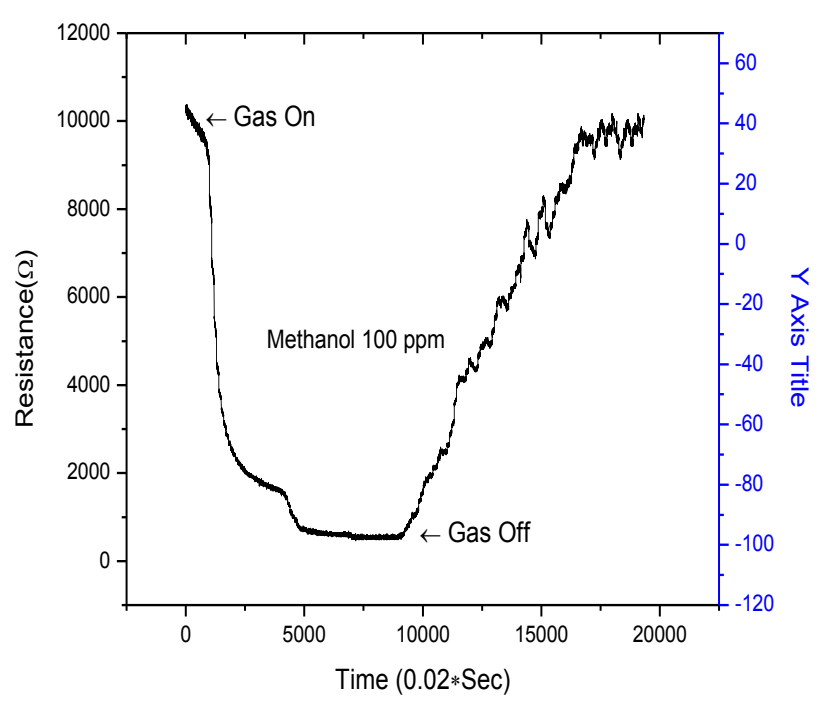

Fig. 8 TGS 822 Methanol Response (Resistance vs. Time) Graph 


\section{CONCLUSION}

The electrical characteristics like sensitivity, selectivity, response time and recovery time of the commercial gas sensor TGS 822 have been studied and discussed. On the basis of results, for TGS 822 it is observed that the response of this gas sensor is nearly about same for each alcohol under test at high temperature $\left(300{ }^{\circ} \mathrm{C}\right)$. Hence, it is concluded that the sensor is not much selective in nature. Further the result obtained with source measure unit are validated with the help of real time monitoring using NI USB 6210. It is also observed that the response time decreases and recovery time increases with increase in the concentration of analyte. Selectivity of the sensor is still a matter of great concern. Dopants can be added to improve the selectivity of the sensors. In real time data acquisition there is a requirement of more number of channels as the number of sensors increases. In order to overcome this problem of requirement of more number of channels temperature modulation and various data processing techniques can be applied.

\section{REFERENCES}

[1] C. Wang, L. Yin, L. Zhang, D. Xiang, and R. Gao, Metal oxide gas sensors: sensitivity and influencing factors, Sensors (Basel), vol. 10, no. 3, Jan. 2010, 2088-106.

[2] M. S. M. Shi, B. G. Bin Guo, and a. Bermak, Redundancy Analysis for Tin Oxide Gas Sensor Array, Third IEEE Int.Work. Electron. Des. Test Appl., 2006, 8-11.

[3] J. Smulko and M. Trawka, New approaches for improving selectivity and sensitivity of resistive gas sensors : A review, $2014,2-4$.

[4] P. Information, TGS 822 - for the detection of Organic Solvent Vapors.

[5] P. Information, TGS 825 - Special Sensor for Hydrogen Sulfide.

[6]G. Neri, First Fifty Years of Chemoresistive Gas Sensors, Chemosensors, vol. 3, 2015, 1-20.

[7] S.A. Waghuley, E. Devices, Tin Dioxide/Polypyrrole Multilayer Chemiresistor As A Hydrogen Sulfide Gas Sensor, vol. 10, 2011, 433-437.

[8] N. I. Usb- and U. Manual, DAQ M Series, no. April, 2009.

[9] G. Korotcenkov, "Metal oxides for solid-state gas sensors: What determines our choice?, Mater. Sci. Eng. B Solid-State Mater Adv. Technol., vol. 139, 2007, 1-23,.

[10] G. Korotcenkov and B. K. Cho, Engineering approaches for the improvement of conductometric gas Sensor parameters, Sensors Actuators B Chem., vol. 188, Nov. 2013, 709-728.

[11] H. Zhang, J. Feng, T. Fei, S. Liu, and T. Zhang, SnO2 nanoparticles-reduced graphene oxide nanocomposites for NO2 sensing at low operating temperature, Sensors Actuators B Chem., vol. 190, no. 2, Jan. 2014, 472-478.

[12] K. Wetchakun, T. Samerjai, N. Tamaekong, C. Liewhiran, C. Siriwong, V. Kruefu, a. Wisitsoraat, a. Tuantranont, and S.Phanichphant, Semiconducting metal oxides as sensors for environmentally hazardous gases, Sensors Actuators B Chem., vol. 160, no. 1, Dec. 2011, 580591.

[13] G. F. Fine, L. M. Cavanagh, A. Afonja, and R. Binions, Metal oxide semi-conductor gas sensors in environmental monitoring, Sensors, vol. 10, no. x, pp. 5469-5502, 2010. 